\title{
Triple negativity and young age as prognostic factors in lymph node-negative invasive ductal carcinoma of $1 \mathrm{~cm}$ or less
}

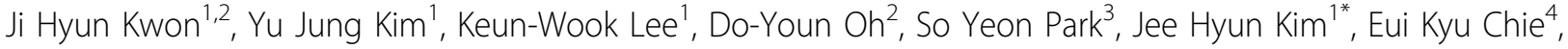 \\ Sung-Won Kim ${ }^{5}$, Seock-Ah Im², In-Ah Kim², Tae-You Kim², In Ae Park , Dong-Young Noh ${ }^{8}$, Yung-Jue Bang ${ }^{2}$, \\ Sung Whan $\mathrm{Ha}^{4}$
}

\begin{abstract}
Background: Whether a systemic adjuvant treatment is needed is an area of controversy in patients with nodenegative early breast cancer with tumor size of $\leq 1 \mathrm{~cm}$, including T1mic.

Methods: We performed a retrospective analysis of clinical and pathology data of all consecutive patients with node-negative T1mic, T1a, and T1b invasive ductal carcinoma who received surgery between Jan 2000 and Dec 2006. The recurrence free survival (RFS) and risk factors for recurrence were identified.

Results: Out of 3889 patients diagnosed with breast cancer, 375 patients were enrolled (T1mic:120, T1a:93, T1b:162). Median age at diagnosis was 49. After a median follow up of 60.8 months, 12 patients developed recurrences (T1mic:4 (3.3\%), T1a:2 (2.2\%), T1b:6 (3.7\%)), with a five-year cumulative RFS rate of 97.2\%. Distant recurrence was identified in three patients. Age younger than 35 years ( $H R \quad 4.91 ; 95 \% \mathrm{Cl} 1.014-23.763, \mathrm{p}=0.048$ ) and triple negative disease ( $\mathrm{HR} 4.93 ; 95 \% \mathrm{Cl} 1.312-18.519, \mathrm{p}=0.018)$ were significantly associated with a higher rate of recurrence. HER2 overexpression, Ki-67, and p53 status did not affect RFS.
\end{abstract}

Conclusions: Prognosis of node-negative breast cancer with T1mic, T1a and T1b is excellent, but patients under 35 years of age or with triple negative disease have a relatively high risk of recurrence.

\section{Background}

Owing to the increased use of screening mammography, the proportion of early stage breast cancer is increasing internationally [1-3]. In Korea, an increase in the percentage of stage 0 and I types of breast cancer has also been reported. The proportion of stage 0 breast cancer was $7.5 \%$ in 2002 and increased to $11.3 \%$ in 2003. For stage I breast cancer, the proportion of patients increased from $29.5 \%$ to $36.5 \%$ over the same period $[4,5]$.

Generally, it has been reported that the prognosis of small-sized, node-negative breast cancer is excellent with complete surgical resection of the primary tumor, even without systemic adjuvant therapy [6]. For patients

\footnotetext{
* Correspondence: jhkimmd@snu.ac.kr

'Department of Internal Medicine, Seoul National University College of Medicine, Seoul National University Bundang Hospital, Seongnam, Korea Full list of author information is available at the end of the article
}

with microinvasive breast cancer, which is defined as tumor foci of $0.1 \mathrm{~cm}$ or less, a very small percentage of women relapse or die of breast cancer [7]. According to an analysis of the Surveillance Epidemiology and End Results (SEER) data from 1998 to 2001, the ten-year overall breast cancer specific mortality of patients with T1a, bNOM0 disease was $4 \%$ [8].

Nevertheless, certain subgroups of patients who were initially diagnosed with small, node-negative breast cancer tumors have a risk of recurrence. Some authors have reported that young patients under 35 years old had poor prognosis [9]. The biological factors of a high grade of tumor $[8,10,11]$ and high Ki-67 [12] were associated with a high relapse or high mortality rate.

There have been few clinical studies with large numbers of patients over a long duration of observation sufficient for the evaluation of the prognosis of node-negative breast cancer of $1 \mathrm{~cm}$ or less in size. In addition, few studies
C Biomed Central

C 2010 Kwon et al; licensee BioMed Central Ltd. This is an Open Access article distributed under the terms of the Creative Commons Attribution License (http://creativecommons.org/licenses/by/2.0), which permits unrestricted use, distribution, and reproduction in any medium, provided the original work is properly cited. 
have evaluated the long-term prognosis according to the hormone receptor and human epidermal growth factor receptor 2 (HER2) statuses because many patients were not examined for estrogen receptor (ER), progesterone receptor (PR), or HER2 status before these tests became widely available. Therefore, some controversy remains regarding treatment decisions for these patients.

The features of breast cancer vary among Asian countries, but there is a common tendency of younger ageonset and a large proportion of premenopausal women $[5,13]$. Some studies have reported higher rates of hormone receptor negative or high-grade breast tumor in Asian populations [14]. However, the ethnic differences associated with recurrence or mortality remain unclear, especially in node-negative early breast cancer of $1 \mathrm{~cm}$ or less.

The aim of this study was to evaluate the overall prognosis of lymph node negative invasive ductal carcinoma of the breast of $\leq 1 \mathrm{~cm}$ in size, including microinvasive carcinoma (T1mic) in a Korean population. Moreover, through identification of subgroups of patients with a high risk of recurrence and their characteristics, we set out to determine which subgroup of patients would be candidates for systemic adjuvant therapies.

\section{Methods}

\section{Study population}

We identified the study population from a prospectively maintained hospital-based cancer registry and collected information from all consecutive women diagnosed as invasive breast carcinoma at Seoul National University Hospital and Seoul National University Bundang Hospital from January 2000 to December 2006. Eligibility criteria included complete surgical resection, histologic diagnosis of invasive ductal carcinoma of $1 \mathrm{~cm}$ or less (T1a, T1b), or microinvasive carcinoma (T1mic) and no lymph node metastasis (NO) according to the fifth and sixth editions of the American Joint Committee on Cancer (AJCC) Cancer Staging Manual [15]. Both the fifth and sixth editions were used because $\mathrm{T}$ staging did not differ between the two staging systems. Patients with a history of previous malignancy of the breast or other sites and who received neoadjuvant chemotherapy were excluded.

\section{Clinical and biological data acquisition}

Data on patient's baseline characteristics and symptoms, mammography results, type of operation and axillary lymph node examinations were collected. The type of operation was divided into mastectomy and breastconserving surgery, and breast-conserving surgery included lumpectomy, quadrantectomy and excision of the primary tumor. Methods of axillary lymph node examination were classified into sentinel lymph node biopsies and axillary lymph node dissections.
Pathologic information was obtained by reviewing pathology reports on the following variables: tumor size, histologic subtype, modified Bloom-Richardson histologic grade (tubule formation, nuclear pleomorphism, mitotic counts), extent of intraductal carcinoma, lymphatic invasion, venous invasion and tumor border. Immunohistochemical data for standard prognostic biomarkers (ER, PR, HER-2, p53 and Ki-67) were also collected. Immunohistochemical staining was determined from microinvasive foci in cases of T1mic disease. For ER and PR, cases with $10 \%$ or more positive staining were grouped as positive. For HER-2, 3+ staining by immunohistochemistry was considered positive. For $\mathrm{Ki}-67$ status, we grouped the cases with $10 \%$ or more positive staining as a positive [16]. A 10\% cutoff value was also used for p53 expression. Information about treatment undertaken as an adjuvant therapy was also retrieved.

Recurrence free survival (RFS) was calculated as the time from operation to diagnosis of a recurrent disease in the ipsilateral breast, local, regional or distant site. For patients who remained alive and recurrence-free, data were censored at the date of the last follow up. The information of recurrent disease included time of diagnosis, sites of disease (local, regional, systemic), and histologic features of recurrent tumor (ductal carcinoma in situ or invasive ductal carcinoma). Diagnosis of contra-lateral breast cancer was not included in the category of recurrent disease. Overall survival was measured as the time from operation to death.

\section{Statistical analysis}

Pearson's chi-square test was used to assess differences in clinical and biological characteristics between $\mathrm{T}$ stage subgroups. The RFS curves were constructed using the Kaplan-Meier method, and the log-rank test was used for a comparison of the survival curves between subgroups according to prognostic factors. We also compared the five-year cumulative survival rate and investigated the association between the probability of death or recurrence and the clinical and biologic features. Multivariate analysis was conducted using Cox's proportional hazard regression model, and our data was shown to satisfy the proportional hazard assumption. A significance level of 0.05 was used for covariate entry.

All statistical analyses were performed using SPSS for Windows software, version 15.0 (SPSS Inc., Chicago, IL). The study was approved by an independent review board at the Seoul National University Bundang Hospital and Seoul National University Hospital.

\section{Results}

\section{Clinical and histologic characteristics}

From January 2000 to December 2006, we identified a total of 3889 women with invasive breast cancer who 
were diagnosed at the Seoul National University Hospital and Seoul National University Bundang Hospital using the hospital cancer registry. Among these, we excluded 2907 patients $(74.7 \%)$ with more advanced stage cancer than T1bN0, 76 patients (1.9\%) who received neoadjuvant chemotherapy, and 81 patients (2.1\%) with recurrent breast cancer. Rest of the patients $(\mathrm{n}=450,11.6 \%)$ received diagnosis but did not undergo operation in our hospital therefore were excluded from the study. A total of 375 (9.6\%) women were eligible, and 120 patients were classified as T1mic, 93 as T1a, and 162 as T1b. Median age was 49 years (range, 24 to 77 years), and 23 patients (6.1\%) were under 35 . The majority of the study population (182 patients, $48.5 \%$ ) was asymptomatic at the time of diagnosis, and these patients were diagnosed by screening mammography. Isolated microcalcification was the most common mammographic finding (149 patients, 40.9\%). Pathologic information including hormone receptor and HER2 status was available in $99 \%$ of patients. Twenty six percent of patients had HER2 positive tumors, defined by $3+$ staining on immunohistochemistry; $67.3 \%$ had hormone receptor positive disease; and $15.1 \%$ had triple negative disease.

Table 1 shows the baseline characteristics of the three $\mathrm{T}$ stage sub-groups. The age distribution between each patient $\mathrm{T}$ stage group was similar. In the microinvasive (T1mic) group, there were significantly higher percentages of negative ER and negative PR disease compared to the T1a and T1b groups ( $57.6 \%$ vs. $34.4 \%, 22.2 \%$ for ER, $68.6 \%$ vs. $48.4 \%, 37.7 \%$ for PR; $\mathrm{p}<0.0001$ ). T1 mic tumor also had a higher proportion of HER2 positivity ( $<<0.0001) ; 54$ patients $(45.8 \%)$ in the T1mic group, 21 $(22.8 \%)$ in T1a, and $21(13.0 \%)$ in T1b. The frequency of positive immunohistochemical staining for p53 was also highest in the T1mic group ( $\mathrm{p}=0.080$ by chi-square, $p=0.037$ by Linear-by-Linear association). Ki-67 did not show significant differences between each patient group. Among the 255 patients with T1a or T1b tumor, data of associated DCIS was available in 248 patients. One-hundred and ninety-eight $(79.8 \%)$ had associated DCIS around the invasive portion, $79(88.8 \%)$ in T1a and $119(73.6 \%)$ in T1b.

\section{Loco-regional and adjuvant treatment}

178 patients $(47.5 \%)$ received a mastectomy, and breastconserving surgery was performed in 197 women (52.5\%). For axillary lymph node examinations, more patients (255 patients, 68\%) received axillary lymph node dissection than sentinel lymph node biopsies. Among patients who received breast-conserving surgery, 135 patients $(68.5 \%)$ were treated with adjuvant radiotherapy after surgical resection. The proportion of patients receiving adjuvant whole breast radiotherapy
Table 1 Baseline characteristics of all patients according to $\mathrm{T}$ stage

\begin{tabular}{|c|c|c|c|c|c|}
\hline & $\begin{array}{c}\text { All } \\
\text { patients } \\
(\mathrm{N}=375)\end{array}$ & $\begin{array}{c}\text { T1mic } \\
(\mathrm{N}=120)\end{array}$ & $\begin{array}{c}\text { T1a } \\
(\mathrm{N}=93)\end{array}$ & $(N=162)$ & $\begin{array}{c}P \\
\text { value }\end{array}$ \\
\hline \multicolumn{6}{|l|}{ Age at diagnosis } \\
\hline Median & 49 & 49 & 47 & 50 & 0.297 \\
\hline Range & $24-77$ & $27-74$ & $29-77$ & $24-73$ & \\
\hline \multicolumn{6}{|l|}{ Grade } \\
\hline 1 & $28(11.2)$ & . & $8(9.0)$ & $20(12.3)$ & 0.126 \\
\hline 2 & $152(60.6)$ & . & $49(55.0)$ & 103(63.6) & \\
\hline 3 & $71(28.3)$ & . & $32(36.0)$ & $39(24.1)$ & \\
\hline \multicolumn{6}{|l|}{$E R^{a}$} \\
\hline Negative & $136(36.5)$ & $68(57.6)$ & $32(34.4)$ & $36(22.2)$ & $<0.001$ \\
\hline Positive & $237(63.5)$ & $50(42.4)$ & $61(65.6)$ & $126(77.8)$ & \\
\hline \multicolumn{6}{|l|}{$P R^{b}$} \\
\hline Negative & $187(50.1)$ & $81(68.6)$ & $45(48.4)$ & $61(37.7)$ & $<0.001$ \\
\hline Positive & $186(49.9)$ & $37(31.4)$ & 48(51.6) & $101(62.3)$ & \\
\hline \multicolumn{6}{|l|}{ HER $2^{c}$} \\
\hline Negative & $276(74.2)$ & $64(54.2)$ & $71(77.2)$ & $141(87.0)$ & $<0.001$ \\
\hline Positive & $96(25.8)$ & $54(45.8)$ & $21(22.8)$ & $21(13.0)$ & \\
\hline \multicolumn{6}{|l|}{ HR/HER2 } \\
\hline $\mathrm{HR}+\mathrm{HER} 2-$ & $220(59.1)$ & $42(35.6)$ & $56(60.9)$ & $122(75.3)$ & $<0.001$ \\
\hline HR+HER2+ & $31(8.3)$ & $11(9.3)$ & $9(9.8)$ & $11(6.8)$ & \\
\hline HR-HER2+ & $65(17.5)$ & $43(36.4)$ & $12(13)$ & $10(6.2)$ & \\
\hline HR-HER2- & $56(15.1)$ & $22(18.6)$ & 15(16.3) & $19(11.7)$ & \\
\hline \multicolumn{6}{|l|}{$p 53^{d}$} \\
\hline$<10 \%$ & $220(60.6)$ & $60(52.2)$ & $56(63.6)$ & 104(65.0) & 0.080 \\
\hline$\geq 10 \%$ & $143(39.4)$ & $55(47.8)$ & $32(36.4)$ & $56(35.0)$ & \\
\hline \multicolumn{6}{|l|}{$\mathrm{Ki}-67^{\mathrm{d}}$} \\
\hline$<10 \%$ & $275(75.8)$ & $82(71.3)$ & $72(81.8)$ & $121(75.6)$ & 0.223 \\
\hline$\geq 10 \%$ & $88(24.2)$ & $33(28.7)$ & $16(18.2)$ & $39(24.4)$ & \\
\hline
\end{tabular}

" Nuclear/histologic grade was assessed only in T1a and T1b patients.

${ }^{\mathrm{a}, \mathrm{b}}$ Data of hormone receptor status was available in 373 patients. $;<10 \%$; negative, $\geq 10 \%$;positive.

' HER2 status was determined by immunohistochemistry and was available in 372 patients.; 0,1+,2+;negative, 3+;positive.

${ }^{\mathrm{d} D a t a}$ of $\mathrm{p} 53$ and $\mathrm{Ki}-67$ was available in 363 patients.

was different in each $\mathrm{T}$ stage group: $30(56.6 \%)$ in $\mathrm{T} 1 \mathrm{mic}, 30(63.8 \%)$ in $\mathrm{T} 1 \mathrm{a}$, and $75(77.3 \%)$ in $\mathrm{T} 1 \mathrm{~b}(\mathrm{p}=$ $0.007)$.

278 patients $(74.1 \%)$ received systemic adjuvant therapy. Among patients with hormone-receptor positive disease, 232 (92.4\%) received adjuvant endocrine therapy. No differences were observed in the percentage of patients undergoing endocrine therapy between $T$ stage subgroups. Adjuvant chemotherapy was given to 61 (16.3\%) patients. Forty-two patients, $34.4 \%$ of the patients with ER and PR negative disease, received adjuvant chemotherapy. An anthracycline-based regimen was given to thirty-three patients $(54.1 \%$ of these 61 patients), and 25 patients were treated with combination 
Table 2 Number of events and five year recurrence free survival according to prognostic factors

\begin{tabular}{|c|c|c|c|c|c|}
\hline Variable & & No. of patients & No. of events & Proportion surviving to 5 years (\%) & $p$ value \\
\hline \multicolumn{6}{|l|}{ T stage } \\
\hline & T1mic & 120 & 4 & 97.4 & 0.681 \\
\hline & T1a & 93 & 2 & 97.8 & \\
\hline & $\mathrm{T} 1 \mathrm{~b}$ & 162 & 6 & 96.9 & \\
\hline \multicolumn{6}{|l|}{ Age } \\
\hline & $\leq 35$ & 23 & 3 & 90.9 & 0.002 \\
\hline & $>35$ & 352 & 9 & 97.7 & \\
\hline \multicolumn{6}{|l|}{ Grade" } \\
\hline & 1 (low) & 28 & 1 & 96.3 & 0.696 \\
\hline & 2 & 152 & 5 & 96.6 & \\
\hline & 3 (high) & 71 & 2 & 98.6 & \\
\hline \multicolumn{6}{|l|}{$E R^{a}$} \\
\hline & negative & 136 & 7 & 95.1 & 0.123 \\
\hline & positive & 237 & 5 & 98.2 & \\
\hline \multicolumn{6}{|l|}{$P R^{b}$} \\
\hline & negative & 187 & 9 & 96.0 & 0.126 \\
\hline & positive & 186 & 3 & 98.2 & \\
\hline \multicolumn{6}{|l|}{$H R$} \\
\hline & ER-PR- & 122 & 7 & 94.9 & 0.069 \\
\hline & ERt and/or PR+ & 251 & 5 & 98.4 & \\
\hline \multicolumn{6}{|l|}{ HER2 ${ }^{c}$} \\
\hline & Negative & 276 & 8 & 97.4 & 0.772 \\
\hline & Positive & 96 & 3 & 97.9 & \\
\hline \multicolumn{6}{|l|}{ HR/HER2 } \\
\hline & HR+HER2- & 220 & 4 & 98.6 & 0.225 \\
\hline & HR+HER2+ & 31 & 1 & 96.8 & \\
\hline & HR-HER2+ & 65 & 2 & 98.5 & \\
\hline & HR-HER2- & 56 & 4 & 92.6 & \\
\hline \multicolumn{6}{|l|}{ HR/HER2 } \\
\hline & HR+ and/or HER2+ & 316 & 7 & 98.4 & 0.018 \\
\hline & HR-HER2- & 56 & 4 & 92.6 & \\
\hline \multicolumn{6}{|l|}{$\mathrm{p} 53^{\mathrm{d}}$} \\
\hline & $<10 \%$ & 220 & 4 & 97.9 & 0.543 \\
\hline & $\geq 10 \%$ & 143 & 6 & 97.1 & \\
\hline \multicolumn{6}{|l|}{$\mathrm{Ki}-67^{\mathrm{d}}$} \\
\hline & $<10 \%$ & 275 & 6 & 98.4 & 0.148 \\
\hline & $\geq 10 \%$ & 88 & 4 & 95.5 & \\
\hline
\end{tabular}

" Only T1a, T1b patients were analyzed using nuclear/histolgogic grade.

${ }^{a, b}$ Data of hormone receptor status was available in 373 patients. $;<10 \%$;negative, $\geq 10 \%$;positive.

c HER2 status was determined by immunohistochemistry and was available in 372 patients.; 0,1+,2+;negative, 3+;positive.

${ }^{\mathrm{d}}$ Data of p53 and i-67 was available in 363 patients.

chemotherapy of cyclophosphamide, methotrexate, fluorouracil. No patients received adjuvant trastuzumab. T1mic patients were more likely to be candidates for observation without any systemic adjuvant therapy (75.8\% in $\mathrm{T} 1 \mathrm{mic}$ group, $53.6 \%$ in $\mathrm{T} 1 \mathrm{a}$, and $38.7 \%$ in T1b, $\mathrm{P}<0.0001)$.

\section{Recurrence and prognosis}

Median follow up duration for all patients was 60.8 months while median RFS duration was not reached as of the time of this writing. The five-year cumulative RFS rate was $97.2 \%$, and recurrent disease was diagnosed in 12 patients during this follow up period. There was no difference in five-year RFS between T1mic, T1a and T1b patients $(97.4 \%$ for T1mic, $97.8 \%$ for $\mathrm{T} 1 \mathrm{a}$, and 96.9\% for $\mathrm{T} 1 \mathrm{~b}, \mathrm{p}=0.681$ ) (Table 2). The rate of local or regional recurrence did not show a statistically significant difference between patients who received or not received adjuvant radiotherapy among the patients who received breast conserving surgery $(\mathrm{p}=0.871)$. 
On the univariate analysis, age younger than 35 years and hormone receptor negative disease were risk factors of recurrence. The five-year cumulative RFS rate was $90.9 \%$ vs. $97.7 \%$ in patients $\leq 35$ and $>35$ years of age $(\mathrm{p}=0.002$, Figure $1 \mathrm{~A})$. Each of ER and PR status did not show a significant association with recurrence, but negative status of both ER and PR tend to be associated with shorter RFS $(\mathrm{p}=0.069)$. Patients with both ER and PR negative disease showed a five-year cumulative RFS rate of 94.9\%; hormone receptor-positive patients showed a rate of $98.4 \%$. Patients with triple negative disease had a significantly lower RFS rate compared to hormone receptor-positive and/or HER2-positive patients ( $\mathrm{p}$ $=0.018$, Figure 1 B). HER2 status alone, Ki-67 and p53 status were not prognostic factors of RFS. Whether adjuvant chemotherapy was given was not associated with the development of systemic recurrence $(p=0.422)$.

Cox proportional hazard regression model was constructed using the variables of age, triple negativity, p53 and $\mathrm{Ki}-67$. The independent prognostic factors of recurrence were triple negativity (HR 4.93; 95\% CI 1.312$18.519, \mathrm{p}=0.018)$, and age younger than 35 years $(\mathrm{HR}$ 4.91; 95\% CI 1.014-23.763, $\mathrm{p}=0.048$ ) (Table 3).

In the analysis of distant disease-free survival, age younger than $35(\mathrm{p}=0.029)$ and negative hormone receptor status $(\mathrm{p}=0.011)$ were the convincing poor

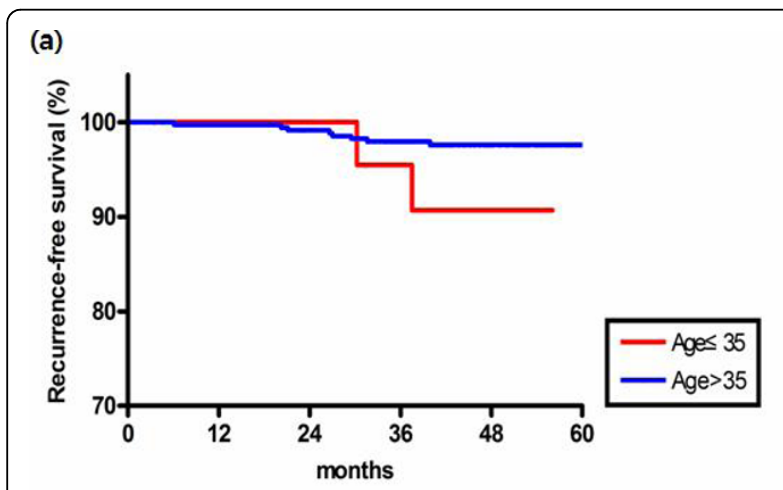

(b)

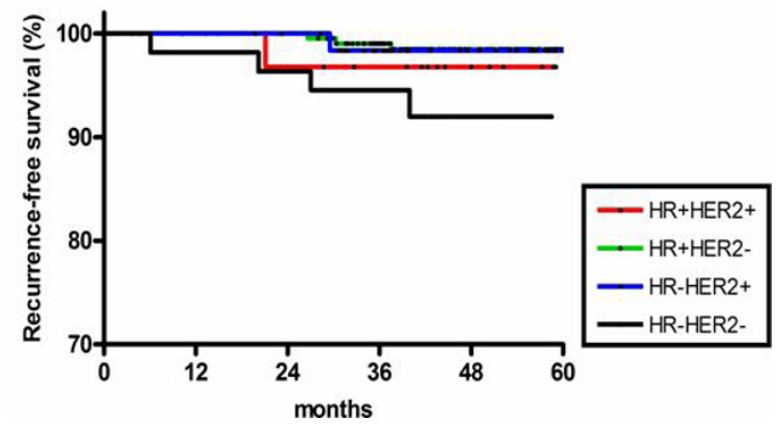

Figure 1 Recurrence-free survival by (a) age (b) breast cancer subtype according to HR and HER2 status.
Table 3 Multivariate analysis: prognostic value of selected factors on recurrence

\begin{tabular}{lccc}
\hline & P value & Hazard ratio & 95\% Confidence interval \\
\hline Triple negative & 0.018 & 4.93 & $1.312-18.519$ \\
Age $(\leq 35)$ & 0.048 & 4.91 & $1.014-23.763$ \\
KI-67 & 0.481 & 1.67 & $0.400-6.995$ \\
p53 & 0.819 & 1.18 & $0.285-4.896$ \\
\hline
\end{tabular}

prognostic factors. Univariate analysis on HER2, Ki67, p53 status and multivariate analysis could not be performed due to the small number of distant metastasis events.

There were twelve patients who experienced recurrence of disease, and their median RFS time was 29.5 months (range 6.1-121.2 months, Table 4). Four patients were diagnosed as T1micN0M0 initially, two patients were T1a, and six were T1b. Three patients were less than 35 years old. Three of 12 patients developed systemic recurrence. All three patients had ER/PR negative disease and developed lung metastases. One patient died during the follow up period. This patient, initially diagnosed with T1bN0M0 breast cancer with ER-PR- and positive HER2, received quadrantectomy with radiation therapy and adjuvant chemotherapy. At 29.5 months after surgical resection, she developed multiple metastases in the lung, skin, and chest wall. She died from breast cancer progression at 40.6 months after surgery.

\section{Discussion}

The results of this study confirmed an excellent shortterm prognosis of lymph-node-negative invasive ductal carcinoma of the breast of $1 \mathrm{~cm}$ or less in a Korean population. Among 375 patients, only one patient died of breast cancer and only twelve cases of recurrence were reported. The overall five-year cumulative RFS rate was $97 \%$. Univariate and multivariate analyses revealed that triple negative status and age younger than 35 years were significantly associated with shorter RFS.

There are a number of studies that focus on the prognosis and predictors of recurrence of node-negative early breast cancer. Though many reviews were retrospective and had small populations, high tumor grade was the most consistent factor associated with poor outcome in these studies [6,17-19]. Chia et al. surveyed 430 , a relatively large number of patients with T1a,b breast cancer. They noted that patients with grade 3 tumor had shorter 10-year RFS compared to grade 1, 2 patients (with $74 \%$ vs. $82 \%, p=0.007$ ) [10]. Age, tumor size, lymphovascular invasion and estrogen receptor negativity were also commonly found to be poor prognostic factors [20-23]. In another report, Ki-67 and p53 were considered as significant prognostic factors of survival [24]. More recently, reports have shown that 
Table 4 Clinicopathologic features of patients with recurrence

\begin{tabular}{|c|c|c|c|c|c|c|c|c|c|}
\hline No. & $\begin{array}{c}\text { Age at } \\
\text { diagnosis }\end{array}$ & $\begin{array}{l}\mathrm{T} \\
\text { stage }\end{array}$ & $\begin{array}{l}\text { Loco-regional } \\
\text { Treatment }\end{array}$ & $\begin{array}{l}\text { Systemic adjuvant } \\
\text { treatment }\end{array}$ & ER & PR & HER2 & $\begin{array}{l}\text { Site of recurrent } \\
\text { disease }\end{array}$ & $\begin{array}{c}\text { RFS } \\
\text { (months) }\end{array}$ \\
\hline 1 & 31 & T1mic & $\mathrm{BCS}$ & None & + & + & - & Remnant breast & 37.5 \\
\hline 2 & 36 & T1mic & $\mathrm{BCS}, \mathrm{RTX}$ & None & + & - & + & Remnant breast & 21.1 \\
\hline 3 & 50 & T1mic & $\mathrm{BCS}, \mathrm{RTX}$ & None & - & - & - & Remnant breast & 20.2 \\
\hline 4 & 35 & T1mic & Mastectomy & None & - & - & + & Lung & 69.9 \\
\hline 5 & 62 & T1a & BCS, RTX & None & - & - & Unknown & Remnant breast & 31.6 \\
\hline 6 & 29 & T1a & Mastectomy & Hormone therapy & + & + & - & Chest wall & 30.3 \\
\hline 7 & 52 & $\mathrm{~T} 1 \mathrm{~b}$ & $\mathrm{BCS}$ & Chemotherapy & - & - & - & Remnant breast & 39.9 \\
\hline 8 & 38 & $\mathrm{~T} 1 \mathrm{~b}$ & BCS, RTX & Chemotherapy & - & - & + & Lung, Skin & 29.5 \\
\hline 9 & 52 & $\mathrm{~T} 1 \mathrm{~b}$ & Mastectomy & None & - & - & - & Lung & 6.1 \\
\hline 10 & 53 & $\mathrm{~T} 1 \mathrm{~b}$ & BCS, RTX & Chemotherapy & - & - & - & Remnant breast & 27 \\
\hline 11 & 38 & $\mathrm{~T} 1 \mathrm{~b}$ & Mastectomy & Hormone therapy & + & + & - & Remnant breast & 26.6 \\
\hline 12 & 60 & $\mathrm{~T} 1 \mathrm{~b}$ & Mastectomy & None & + & - & - & Remnant breast & 121.2 \\
\hline
\end{tabular}

Abbreviation: BCS, breast conserving surgery; RTx, radiotherapy.

HER2-positive disease is a risk factor of recurrence in node-negative tumors $1 \mathrm{~cm}$ or smaller [25]. However, most studies on the prognosis of node-negative early breast cancer were performed in Western countries. In contrast, few studies exist regarding the biology and prognosis of Asian breast cancer patients.

In the present study, triple negative status and age younger than 35 were the only independent prognostic factors of recurrence. Other studies have reported similar results in which younger patients showed poorer prognosis than older patients. These authors suggested that poor prognosis observed in young patients under the age of 35 was related to adverse characteristics of their disease, such as a high proportion of node-positive disease, a high proportion of negative estrogen hormone receptor, and a high proliferation index. However, age younger than 35 years remained an independent poor prognostic factor in the multivariate analysis. However, an analysis of the prognosis of a specific subgroup with tumor sizes of $1 \mathrm{~cm}$ or less was not performed in this study [9]. In our patients, there were no differences in pathologic characteristics of hormone receptor status or HER2 status according to age group (Table 5). Our data suggest that age younger than 35 is an independent risk factor for recurrence, even in patients with nodenegative breast cancer $1 \mathrm{~cm}$ or less in size. Therefore, young age less than 35 should be regarded as a poor prognostic factor when adjuvant therapy is considered. This is important, especially for Asian patients, because the proportion of young women in Asian countries is higher than in Western countries [5,26].

The grade of HER2 overexpression which was a poor prognostic factor in other studies $[24,25,27,28]$ did not have an effect on RFS in our study. This discrepancy can be attributed to the fact that HER2 fluorescence in situ hybridization (FISH) was not performed in most of the patients. There is a possibility that HER2 FISH positive disease was classified as HER2 negative based on immunohistochemical staining only. A literature show that quite a few patients with moderate expression $(+2)$ of HER2 in immunohistochemistry had HER2 gene amplification at FISH [29]. Another explanation for the lack of an association between HER2 status and recurrence may be the inclusion of $\mathrm{T} 1 \mathrm{mic}$ disease in the analysis. Patients with T1mic disease have a higher proportion of HER2 positive disease but a very low potential of systemic metastasis or recurrence. In our series, endocrine unresponsiveness and positive HER2 immunohistochemical staining $(+3)$ were more common in $\mathrm{T} 1 \mathrm{mic}$ tumor than $\mathrm{T} 1 \mathrm{a}$ or $\mathrm{T} 1 \mathrm{~b}$ disease. The reason for high HER2 positive rate in $\mathrm{T} 1 \mathrm{mic}$ tumor is not

Table 5 Pathologic characteristics according to age group

\begin{tabular}{lccc}
\hline & Age $\leq \mathbf{3 5}$ (\%) & Age > 35 (\%) & P value \\
\hline $\begin{array}{l}\text { Hormone receptor (HR) } \\
\text { ER+ and/or PR+ }\end{array}$ & $14(60.9)$ & $237(67.7)$ & 0.498 \\
$\quad$ ER-PR- & $9(39.1)$ & $113(32.3)$ & \\
HER2 & & & \\
$\quad$ Negative & $8(34.8)$ & $88(25.2)$ & 0.328 \\
$\quad$ Positive & $15(65.2)$ & $261(74.8)$ & \\
HR/HER2 & & & \\
$\quad$ HR+ and/or HER2+ & $19(82.6)$ & $297(85.1)$ & 0.763 \\
$\quad$ HR-HER2- & $4(17.4)$ & $52(14.9)$ & \\
p53 & $13(59.1)$ & $207(60.7)$ & 1.000 \\
$\quad<10 \% ;$ & $9(40.9)$ & $134(39.3)$ & \\
$\quad \geq 10 \%$ & $15(68.2)$ & $260(76.2)$ & 0.441 \\
Ki-67 & $7(31.8)$ & $81(23.8)$ & \\
$\quad<10 \%$ & & & \\
$\quad \geq 10 \%$ & &
\end{tabular}

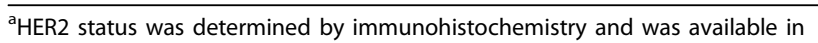
372 patients.; 0,1+,2+;negative, 3+;positive. 
clearly understood, but other literatures also report the similar findings [12,30].

More than half of all patients received breastconserving surgery in our study, but $31.5 \%$ of these patients, mainly $\mathrm{T} 1 \mathrm{mic}$ or $\mathrm{T} 1 \mathrm{a}$, did not receive postoperative radiotherapy because the tumor size was extremely small. The local recurrence rate of this group was $3.2 \%$ ( 2 in 62 patients), which was not high compared to the patients who received adjuvant radiotherapy $(2.9 \%, 4$ in 135 patients). This may have resulted from the very low incidence of recurrence itself; hence, a longer duration of follow up and a larger number of patients are necessary before definitive conclusions can be made regarding the role of post-operative radiotherapy in very small breast cancer.

Our study has several limitations. First, recurrence of early breast cancer is known to be discovered not only during the first decade of follow up, but also during the second decade or even later. Therefore, our duration of follow up was not sufficient for an evaluation of breast cancer prognosis regarding the overall survival and long-term recurrence rate, especially in endocrineresponsive disease. However, an analysis of the shortterm recurrence rate and risk factors would be valuable for the identification of specific patient groups who require systemic adjuvant chemotherapy after surgery. Second, other important pathological information, such as mitotic activity [31,32] and vascular invasion [33] were not included in this analysis. Third, many patients received systemic adjuvant therapy according to their hormone receptor status and other clinical factors. Therefore, we cannot conclude whether the pattern of recurrence reflects the natural history of specific subgroups or a response to the adjuvant therapies given. In fact, $92.4 \%$ of hormone receptor positive patients received endocrine therapy while $34.5 \%$ of hormone receptor negative patients were treated with adjuvant chemotherapy. It is within the realm of possibility that good prognosis of a patients group with positive ER or PR status was caused by the efficacy of the adjuvant hormonal therapy. In addition, ER and PR positivity was defined as $10 \%$ or more staining unlike definitions used in recent studies focusing on breast cancer subtypes, which classified tumors as hormone-receptor positive if $1 \%$ or more of tumor nuclei were stained [34]. However, we regarded the tumor with $10 \%$ or more positive staining as hormone receptor-positive disease, because the pathology report of our patients, especially who were diagnosed in the early 2000s, used the previous classification standard. There may be a possibility that tumors with positive staining of ER and or PR between 1-9\% may have been classified as HR negative.

Finally, a definite conclusion pertaining to the subgroup of patients who required systemic adjuvant treatment could not be determined because a multivariate analysis could not be performed for predictors of systemic recurrence due to the low number of events.

\section{Conclusion}

We confirmed that patients with a tumor size of $1 \mathrm{~cm}$ or less of node-negative invasive ductal carcinoma of the breast have excellent short term prognosis. Studies with a larger sample size and a longer follow up duration are needed for confirmation of this result, but patients younger than 35 years of age and triple negative disease were identified to be the highest risk group of recurrence.

\section{Acknowledgements}

Medical Research Collaboration Center in Seoul National University Hospital contributed toward this study by statistic analysis.

This study was supported in part by a grant from the Korean Health 21 R\&D Project, Ministry of Health \& Welfare, Republic of Korea (0412-CR01-07040001).

\section{Author details}

${ }^{1}$ Department of Internal Medicine, Seoul National University College of Medicine, Seoul National University Bundang Hospital, Seongnam, Korea. ${ }^{2}$ Department of Internal Medicine, Seoul National University College of Medicine, Seoul National University Hospital, Seoul, Korea. ${ }^{3}$ Department of Pathology, Seoul National University College of Medicine, Seoul National University Bundang Hospital, Seongnam, Korea. ${ }^{4}$ Department of Radiation Oncology, Seoul National University College of Medicine, Seoul National University Hospital, Seoul, Korea. ${ }^{5}$ Department of Surgery, Seoul National University College of Medicine, Seoul National University Bundang Hospital, Seongnam, Korea. ${ }^{6}$ Department of Radiation Oncology, Seoul National University College of Medicine, Seoul National University Bundang Hospital, Seongnam, Korea. ${ }^{7}$ Department of Pathology, Seoul National University College of Medicine, Seoul National University Hospital, Seoul, Korea. ${ }^{8}$ Department of Surgery, Seoul National University College of Medicine, Seoul National University Hospital, Seoul, Korea.

\section{Authors' contributions}

$\mathrm{JH}$ Kwon, JH Kim conceived of the study, and participated in its design of the study, coordination, and performed data acquisition, statistical analysis, and interpretation. SYP, EKC, SWK, IAK, TYK, IAP, DYN, YJB and SWH have been involved in revising it critically for important intellectual content. JH Kwon, YJK, KWL, DYO, JH Kim and SAI participated in drafting the manuscript. SAI, TYK, YJB have given final approval of the version to be published. All authors read and approved the final manuscript.

\section{Competing interests}

The authors declare that they have no competing interests.

Received: 31 May 2010 Accepted: 15 October 2010

Published: 15 October 2010

\section{References}

1. Otto SJ, Fracheboud J, Looman CW, Broeders MJ, Boer R, Hendriks JH, Verbeek AL, de Koning HJ: Initiation of population-based mammography screening in Dutch municipalities and effect on breast-cancer mortality: a systematic review. Lancet 2003, 361(9367):1411-1417.

2. Berry DA, Cronin KA, Plevritis SK, Fryback DG, Clarke L, Zelen M, Mandelblatt JS, Yakovlev AY, Habbema JD, Feuer EJ: Effect of screening and adjuvant therapy on mortality from breast cancer. $N$ Engl J Med 2005, 353(17):1784-1792.

3. Duijm LE, Groenewoud JH, Roumen RM, de Koning HJ, Plaisier ML, Fracheboud J: A decade of breast cancer screening in The Netherlands: trends in the preoperative diagnosis of breast cancer. Breast Cancer Res Treat 2007, 106(1):113-119. 
4. Son BH, Kwak BS, Kim JK, Kim HJ, Hong SJ, Lee JS, Hwang UK, Yoon HS, Ahn SH: Changing patterns in the clinical characteristics of Korean patients with breast cancer during the last 15 years. Arch Surg 2006, 141(2):155-160.

5. Ahn $\mathrm{SH}$ : Clinical characteristics of breast cancer patients in Korea in 2000. Arch Surg 2004, 139(1):27-30, discussion 31.

6. Joensuu H, Pylkkanen L, Toikkanen S: Late mortality from pT1N0M0 breast carcinoma. Cancer 1999, 85(10):2183-2189.

7. Cavaliere A, Scheibel M, Bellezza G, Colella R, Vitali R, Gori S, Aristei C, Rulli A, Sidoni A: Ductal carcinoma in situ with microinvasion: clinicopathologic study and biopathologic profile. Pathol Res Pract 2006, 202(3):131-135.

8. Hanrahan EO, Gonzalez-Angulo AM, Giordano SH, Rouzier R, Broglio KR, Hortobagyi GN, Valero V: Overall survival and cause-specific mortality of patients with stage T1a,bN0M0 breast carcinoma. J Clin Oncol 2007, 25(31):4952-4960.

9. Fisher B, Dignam J, Tan-Chiu E, Anderson S, Fisher ER, Wittliff JL, Wolmark N: Prognosis and treatment of patients with breast tumors of one centimeter or less and negative axillary lymph nodes. $J$ Nat/ Cancer Inst 2001, 93(2):112-120.

10. Chia SK, Speers CH, Bryce CJ, Hayes MM, Olivotto IA: Ten-year outcomes in a population-based cohort of node-negative, lymphatic, and vascular invasion-negative early breast cancers without adjuvant systemic therapies. J Clin Oncol 2004, 22(9):1630-1637.

11. Soerjomataram I, Louwman MW, Ribot JG, Roukema JA, Coebergh JW: An overview of prognostic factors for long-term survivors of breast cancer. Breast Cancer Res Treat 2008, 107(3):309-330.

12. Colleoni M, Rotmensz N, Peruzzotti G, Maisonneuve P, Viale G, Renne G, Casadio $C$, Veronesi $P$, Intra $M$, Torrisi $R$, et al: Minimal and small size invasive breast cancer with no axillary lymph node involvement: the need for tailored adjuvant therapies. Ann Oncol 2004, 15(11):1633-1639.

13. Choi DH, Shin DB, Lee MH, Lee DW, Dhandapani D, Carter D, King BL, Haffty BG: A comparison of five immunohistochemical biomarkers and HER-2/neu gene amplification by fluorescence in situ hybridization in white and Korean patients with early-onset breast carcinoma. Cancer 2003, 98(8):1587-1595.

14. Agarwal G, Pradeep PV, Aggarwal V, Yip CH, Cheung PS: Spectrum of breast cancer in Asian women. World J Surg 2007, 31(5):1031-1040.

15. Cancer AJCo: AJCC Cancer Staging Manual. New York, NY: Springer, 6 2002.

16. Jung SY, Han W, Lee JW, Ko E, Kim E, Yu JH, Moon HG, Park IA, Oh DY, Im SA, et al: Ki-67 expression gives additional prognostic information on St. Gallen 2007 and Adjuvant! Online risk categories in early breast cancer. Ann Surg Oncol 2009, 16(5):1112-1121.

17. Stierer M, Rosen HR, Weber R, Marczell A, Kornek GV, Czerwenka E: Long term analysis of factors influencing the outcome in carcinoma of the breast smaller than one centimeter. Surg Gynecol Obstet 1992, 175(2):151-160.

18. Leitner SP, Swern AS, Weinberger D, Duncan LJ, Hutter RV: Predictors of recurrence for patients with small (one centimeter or less) localized breast cancer (T1a,b N0 M0). Cancer 1995, 76(11):2266-2274.

19. Joensuu H, Isola J, Lundin M, Salminen T, Holli K, Kataja V, Pylkkanen L, Turpeenniemi-Hujanen T, von Smitten K, Lundin J: Amplification of erbB2 and erbB2 expression are superior to estrogen receptor status as risk factors for distant recurrence in pT1N0M0 breast cancer: a nationwide population-based study. Clin Cancer Res 2003, 9(3):923-930.

20. Trudeau ME, Pritchard KI, Chapman JA, Hanna WM, Kahn HJ, Murray D, Sawka CA, Mobbs BG, Andrulis I, McCready DR, et al: Prognostic factors affecting the natural history of node-negative breast cancer. Breast Cancer Res Treat 2005, 89(1):35-45.

21. Quiet CA, Ferguson DJ, Weichselbaum RR, Hellman S: Natural history of node-negative breast cancer: a study of 826 patients with long-term follow-up. J Clin Oncol 1995, 13(5):1144-1151.

22. Colleoni M, Rotmensz N, Peruzzotti G, Maisonneuve P, Orlando L, Ghisini R, Viale $G$, Pruneri $G$, Veronesi $P$, Luini $A$, et al: Role of endocrine responsiveness and adjuvant therapy in very young women (below 35 years) with operable breast cancer and node negative disease. Ann Oncol 2006, 17(10):1497-1503.

23. Ponzone R, Montemurro F, Maggiorotto F, Robba C, Gregori D, Jacomuzzi ME, Kubatzki F, Marenco D, Dominguez A, Biglia N, et al: Clinical outcome of adjuvant endocrine treatment according to PR and HER-2 status in early breast cancer. Ann Oncol 2006, 17(11):1631-1636.

24. Railo M, Lundin J, Haglund C, von Smitten K, Nordling S: Ki-67, p53, ER receptors, ploidy and $S$ phase as long-term prognostic factors in $\mathrm{T} 1$ node-negative breast cancer. Tumour Biol 2007, 28(1):45-51.

25. Rakkhit RBK, Peintinger F, Cardoso F, Hanrahan EO, Litton JK, Sahin A, Larsimont D, Meric-Bernstam F, Buchholz TA, Valero V, Theriault RL, Piccart M, Ravdin P, Hortobagyi GN, Gonzalez-Angulo AM: Significant increased recurrence rates among breast cancer patients with HER2positive, T1a,bN0M0 tumors. Abstract. The 31th CTRC-AACR San Antonio Breast Cancer Symposium 2008.

26. Ahn SH, Son BH, Kim SW, Kim SI, Jeong J, Ko SS, Han W: Poor outcome of hormone receptor-positive breast cancer at very young age is due to tamoxifen resistance: nationwide survival data in Korea-a report from the Korean Breast Cancer Society. J Clin Oncol 2007, 25(17):2360-2368.

27. Parker SL, Tong T, Bolden S, Wingo PA: Cancer statistics, 1997. CA Cancer J Clin 1997, 47(1):5-27.

28. Tovey SM, Brown S, Doughty JC, Mallon EA, Cooke TG, Edwards J: Poor survival outcomes in HER2-positive breast cancer patients with lowgrade, node-negative tumours. $\mathrm{Br} J$ Cancer 2009, 100(5):680-683.

29. Torrisi R, Rotmensz N, Bagnardi V, Viale G, Curto BD, Dell'orto P, Veronesi $P$, Luini A, D'Alessandro C, Cardillo A, et al: HER2 status in early breast cancer: relevance of cell staining patterns, gene amplification and polysomy 17. Eur J Cancer 2007, 43(16):2339-2344.

30. Park SY, Lee HE, Li H, Shipitsin M, Gelman R, Polyak K: Heterogeneity for stem cell-related markers according to tumor subtype and histologic stage in breast cancer. Clin Cancer Res 16(3):876-887.

31. Menard S, Balsari A, Tagliabue E, Camerini T, Casalini P, Bufalino R, Castiglioni F, Carcangiu ML, Gloghini A, Scalone S, et al: Biology, prognosis and response to therapy of breast carcinomas according to HER2 score. Ann Oncol 2008, 19(10):1706-1712.

32. Louwman WJ, van Beek MW, Schapers RF, Nolthenius-Puylaert MB, van Diest PJ, Roumen RM, Coebergh JW: Long-term survival of T1 and T2 lymph node-negative breast cancer patients according to Mitotic Activity Index: a population-based study. Int J Cancer 2006, 118(9):2310-2314.

33. Baak JP, van Diest PJ, Janssen EA, Gudlaugsson E, Voorhorst FJ, van der Wall E, Vermorken JB: Proliferation accurately identifies the high-risk patients among small, low-grade, lymph node-negative invasive breast cancers. Ann Oncol 2008, 19(4):649-654.

34. Hugh J, Hanson J, Cheang MC, Nielsen TO, Perou CM, Dumontet C, Reed J, Krajewska M, Treilleux I, Rupin M, et al: Breast cancer subtypes and response to docetaxel in node-positive breast cancer: use of an immunohistochemical definition in the BCIRG 001 trial. J Clin Oncol 2009, 27(8):1168-1176.

\section{Pre-publication history}

The pre-publication history for this paper can be accessed here: http://www.biomedcentral.com/1471-2407/10/557/prepub

doi:10.1186/1471-2407-10-557

Cite this article as: Kwon et al:: Triple negativity and young age as prognostic factors in lymph node-negative invasive ductal carcinoma of $1 \mathrm{~cm}$ or less. BMC Cancer 2010 10:557.

\section{Submit your next manuscript to BioMed Central and take full advantage of:}

- Convenient online submission

- Thorough peer review

- No space constraints or color figure charges

- Immediate publication on acceptance

- Inclusion in PubMed, CAS, Scopus and Google Scholar

- Research which is freely available for redistribution

Submit your manuscript at www.biomedcentral.com/submit
Biomed Central 